\title{
Martensitic transformation and stress relaxation in cold-deformed metastable steels
}

\author{
L. Kaputkina and A. Skugorev ${ }^{\mathrm{a}}$ \\ State Technological University "Moscow Institute of Steel and Alloys”, Moscow 119049, Russia
}

\begin{abstract}
The elastic aftereffect and stress relaxation after testing in stable and metastable sheet steels of different structural classes subjected to monotonic and alternating loading under various conditions have been studied. Dependence of the material mechanical behavior and distribution of residual stresses on the strength, possibilities of phase transformations under load and sequence of alternating loading have been shown. A mathematical model for stamping test of sheet steels taking into account phase transformations and stress relaxation has been developed.
\end{abstract}

\section{Introduction}

The information on phase transformations, stress relaxation, structure and property changes during monotonic and sign-variable straining has been necessary for development an adequate model for mechanical behavior of metastable material in stamping. The existing models of sheet product test for stamping and elastic aftereffect do not take into account martensitic transformation under loading and stress relaxation during post-deformation exposure under load or simply introduce corrections from deformation-induced martensitic transformation under loading [1] or limit calculation by low-strain area [2]. Therefore, the object of this work is experimental study of the influence of phase transformations under loading in metastable sheet steel on numerical parameters of elastic aftereffect for sheet material and development of test analytical model which take into account phase transformations and stress relaxation.

\section{Experimental}

Phase and structural changes as well as elastic aftereffect were studied after cold stamping (U-test) of samples made from sheet steels of different structural classes (Table 1): ferritic cold-rolled and annealed steels C08Al and C01AlTi, stainless steel with a completely austenitic structure, and metastable high-nitrogen austeniticmartensitic and martensitic-austenitic high-strength stainless steel with various phase compositions in initial state and different mechanical stability of retained austenite.

After removing a load, the shape and dimensions of the formed article change due to an elastic aftereffect. The main advantage of this testing mode is a possibility to obtain a complex stress state in the vertical sections of the article. Particularly, this is an alternating bending with tension, and this state determines the residual shape of a certain section (Fig. 1) [3]. The elastic aftereffect can be evaluated using several shape deviation parameters of the formed article with respect to the die shape; these include angular parameters $\alpha$ and $\beta$ and the radius of residual curvature $R$ of the vertical section of the article (see Fig. 1). The smaller the angles $\alpha$ and $\beta$ provided the radius of residual curvature $R \rightarrow \infty$, the closer the article shape to the die shape, and the weaker the elastic aftereffect after unloading of the article.

\footnotetext{
${ }^{a}$ skugorev@mail.ru
}

This is an Open Access article distributed under the terms of the Creative Commons Attribution-Noncommercial License (http://creativecommons.org/licenses/by-nc/3.0/), which permits unrestricted use, distribution, and reproduction in any noncommercial medium, provided the original work is properly cited. 
Table 1. Chemical composition and structure of the steels under study

\begin{tabular}{|c|c|c|c|c|c|c|c|c|c|c|c|c|c|c|}
\hline \multirow{2}{*}{ Steel grade } & \multicolumn{13}{|c|}{ Chemical composition ${ }^{*}$, wt $\%$} & \multirow{2}{*}{ Structure } \\
\hline & $\mathrm{Si}$ & Mn & $\mathrm{Cr}$ & $\mathrm{Ni}$ & $\mathrm{Ti}$ & $\mathrm{Al}$ & $\mathrm{Cu}$ & $\mathrm{V}$ & $\mathrm{Nb}$ & Mo & {$[N]$} & {$[\mathrm{C}]$} & {$[\mathrm{S}]$} & \\
\hline C01AlTi & 0,02 & 0,14 & - & - & 0,07 & 0,05 & - & - & - & - & 0,006 & 0,004 & 0,009 & \multirow{2}{*}{ Ferrite } \\
\hline C08Al & 0,03 & 0,35 & - & - & - & 0,05 & - & - & - & - & 0,007 & 0,07 & 0,025 & \\
\hline Cr18Ni10Ti & 0,47 & 0,67 & 17,05 & 9,92 & 0,38 & - & 0,22 & - & - & 0,08 & 0,013 & 0,07 & 0,006 & \multirow{4}{*}{ Austenite } \\
\hline $\mathrm{Cr} 15 \mathrm{Ni} 7 \mathrm{Cu} 2 \mathrm{MoVTiN}$ & 0,38 & 0,76 & 14,8 & 7,75 & 0,052 & - & 2,0 & 0,28 & - & 1,55 & 0,136 & 0,047 & $\mathrm{n} / \mathrm{a}$ & \\
\hline Cr14Ni9Cu2MoVTiN & 0,12 & 0,45 & 14,35 & 9,5 & 0,042 & - & 2,0 & 0,235 & - & 1,48 & 0,119 & 0,042 & $\mathrm{n} / \mathrm{a}$ & \\
\hline $\mathrm{Cr} 22 \mathrm{NMn} 15 \mathrm{Ni} 8 \mathrm{Mo} 2 \mathrm{~V}$ & 0,41 & 14,18 & 21,85 & 7,55 & - & - & - & 0,19 & - & 1,59 & 0,47 & 0,09 & $\mathrm{n} / \mathrm{a}$ & \\
\hline $\mathrm{Cr} 15 \mathrm{Ni} 5 \mathrm{Cu} 2 \mathrm{MoNbTi}$ & 0,48 & 0,65 & 14,0 & 5,7 & 0,07 & - & 2,1 & - & 0,28 & 1,5 & - & 0,07 & $\mathrm{n} / \mathrm{a}$ & \multirow{4}{*}{$\begin{array}{l}\text { Austenite and } \\
\text { martensite }\end{array}$} \\
\hline Cr15Ni5Cu2MoVTiN & 0,14 & 0,71 & 15,5 & 5,29 & 0,06 & - & 1,86 & 0,24 & - & 1,52 & 0,126 & 0,045 & $\mathrm{n} / \mathrm{a}$ & \\
\hline $\mathrm{Cr} 16 \mathrm{Ni} 5 \mathrm{Cu} 2 \mathrm{MoVTiN}$ & 0,14 & 0,58 & 15,75 & 5,38 & 0,035 & - & 1,87 & 0,22 & - & 1,52 & 0,131 & 0,046 & $\mathrm{n} / \mathrm{a}$ & \\
\hline $\mathrm{Cr} 14 \mathrm{Ni} 4 \mathrm{MoCuNbN}$ & 0,22 & 1,05 & 14,6 & 4,68 & - & - & 0,41 & - & 0,06 & 1,89 & 0,091 & 0,117 & 0,007 & \\
\hline $\mathrm{Cr} 18 \mathrm{Ni} 6 \mathrm{Cu} 2 \mathrm{MoTi}$ & 0,4 & 0,52 & 18,0 & 6,0 & 0,07 & - & 1,9 & - & - & 1 & - & 0,07 & $\mathrm{n} / \mathrm{a}$ & \multirow{2}{*}{$\begin{array}{c}\text { Martensite, ferrite and } \\
\text { austenite }\end{array}$} \\
\hline $\mathrm{Cr} 18 \mathrm{Ni2Mn} 2 \mathrm{VN}$ & $\mathrm{n} / \mathrm{a}$ & 1,85 & 18,02 & 2,1 & - & - & - & 0,12 & - & - & 0,09 & 0,05 & $\mathrm{n} / \mathrm{a}$ & \\
\hline
\end{tabular}

${ }^{*}$ Fe for balance

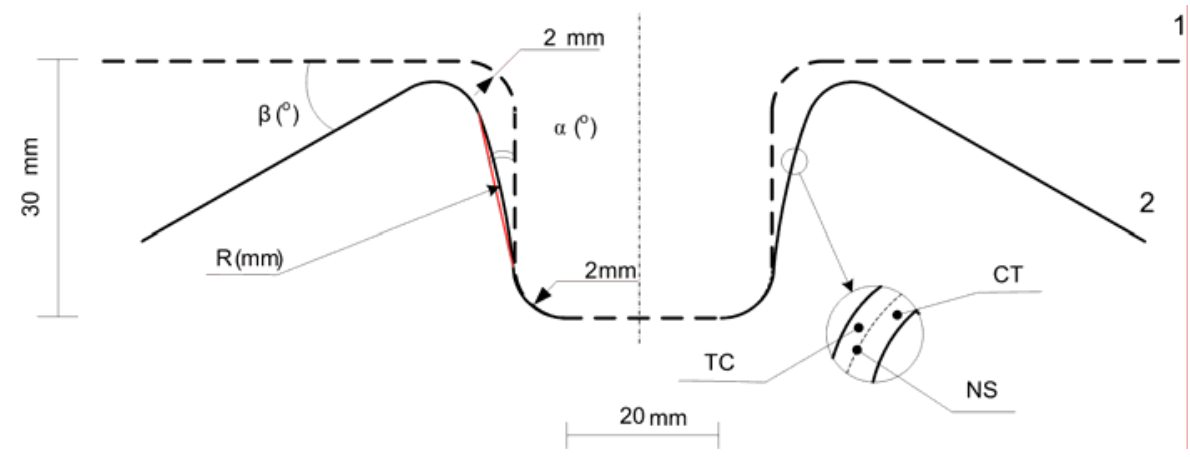

Fig. 1. Schematic representation for the determination of the elastic aftereffect parameters of steel samples: (1) sample profile in a die; (2) sample profile after unloading. NS is the neutral cross-section, TC and CT are the tension-compression and compression-tension zones, respectively.

The mechanical properties and hardening of a material after deformation were estimated using uniaxial tensile tests (State Standard GOST 11701-84) and Vickers hardness measurements (State Standard GOST 299975). The hardness was measured at both sides of a formed sample in the zones with different sequence of an alternating stress state: tension followed by compression (TC) or compression followed by tension (CT; see Fig. 1). Phase composition of steel has been defined from $X$-ray diffraction study using the method accounting for the crystallographic texture of material. X-ray diffractograms have been taken from two external surfaces of the vertical section after deformation and in initial state. The stress relaxation has been studied in the tensile test after true plastic strain of $\mathrm{e}=0.05$ for high-tensile stainless steels $\mathrm{Cr} 18 \mathrm{Ni} 6 \mathrm{Cu} 2 \mathrm{MoTi}, \mathrm{Cr} 15 \mathrm{Ni}$ Cu2MoNbTi and $\mathrm{Cr} 14 \mathrm{Ni} 4 \mathrm{MoCuNbN}$ and after $\mathrm{e}=0.1$ for other steels.

The residual stresses in the deformed material were determined using the X-ray $\sin ^{2} \psi$ method [4] for two external surfaces of the vertical section.

\section{Results and discussion}

The true stress - plastic strain tensile diagrams are shown in Fig. 2. The austenitic-martensitic and multiphase metastable steels have greatest yield stress and deformation hardening. The stable austenitic steels and ferritic steels C08Al and C01AlTi manifest the highest plastic elongation. 


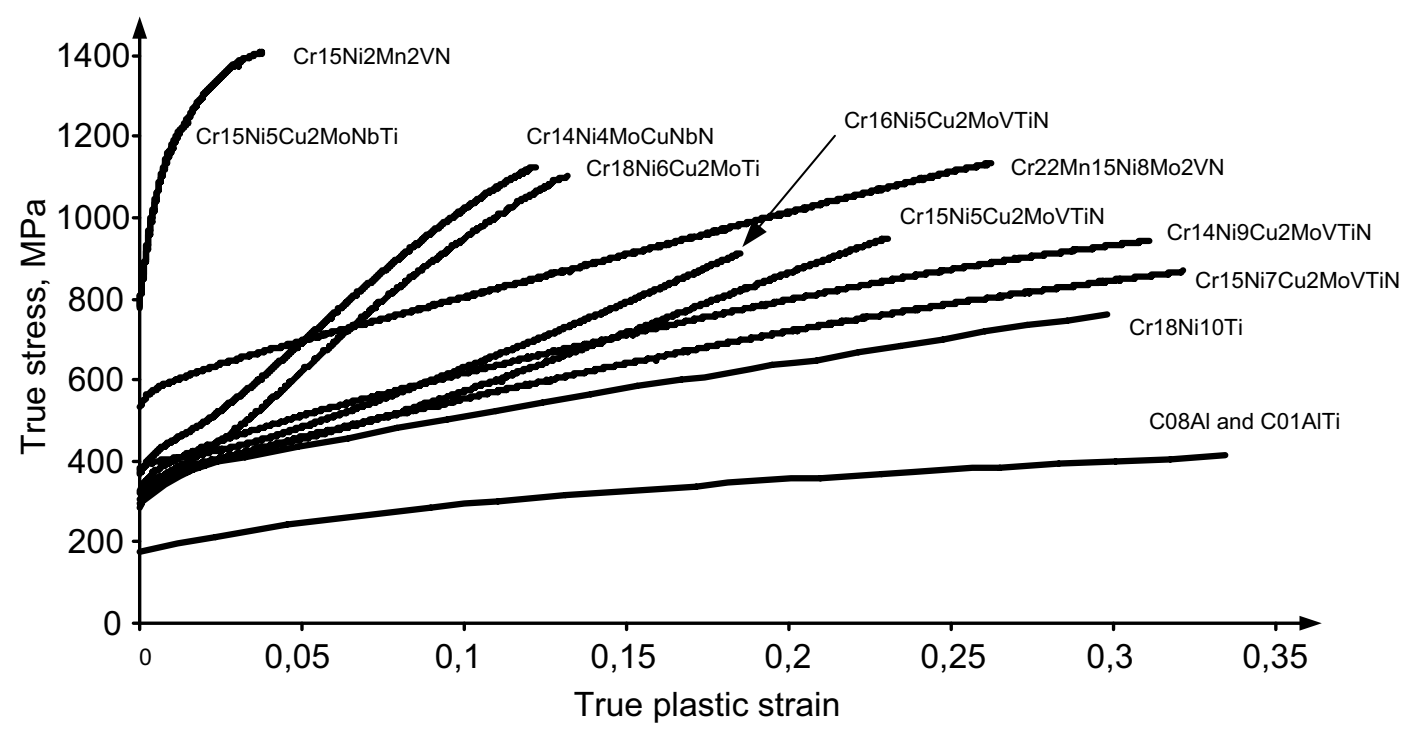

Fig. 2. Ttrue stress - plastic strain diagrams.

The results of the elastic aftereffect measurement depend on structure and mechanical properties of a steel (Fig. 3). The elastic aftereffect of stainless steels is larger in comparison with the ferritic C08Al steel. The elastic aftereffect of metastable austenitic-martensitic steel in which the martensitic transformation is not completed and greatly depends on the sequence of alternating loading ( $\mathrm{Cr} 15 \mathrm{Ni} 5 \mathrm{Cu} 2 \mathrm{MoVTiN}$ and $\mathrm{Cr} 16 \mathrm{Ni}$ Cu2MoVTiN steels) is virtually equal to that for stable austenitic stainless steels (steel Cr18Ni10 Ti and other), while the hardness of the metastable steels is much greater. This, in fact, is explained by the influence of martensitic transformation under loading as well as of alternating loading sequence on the martensitic transformation intensity.

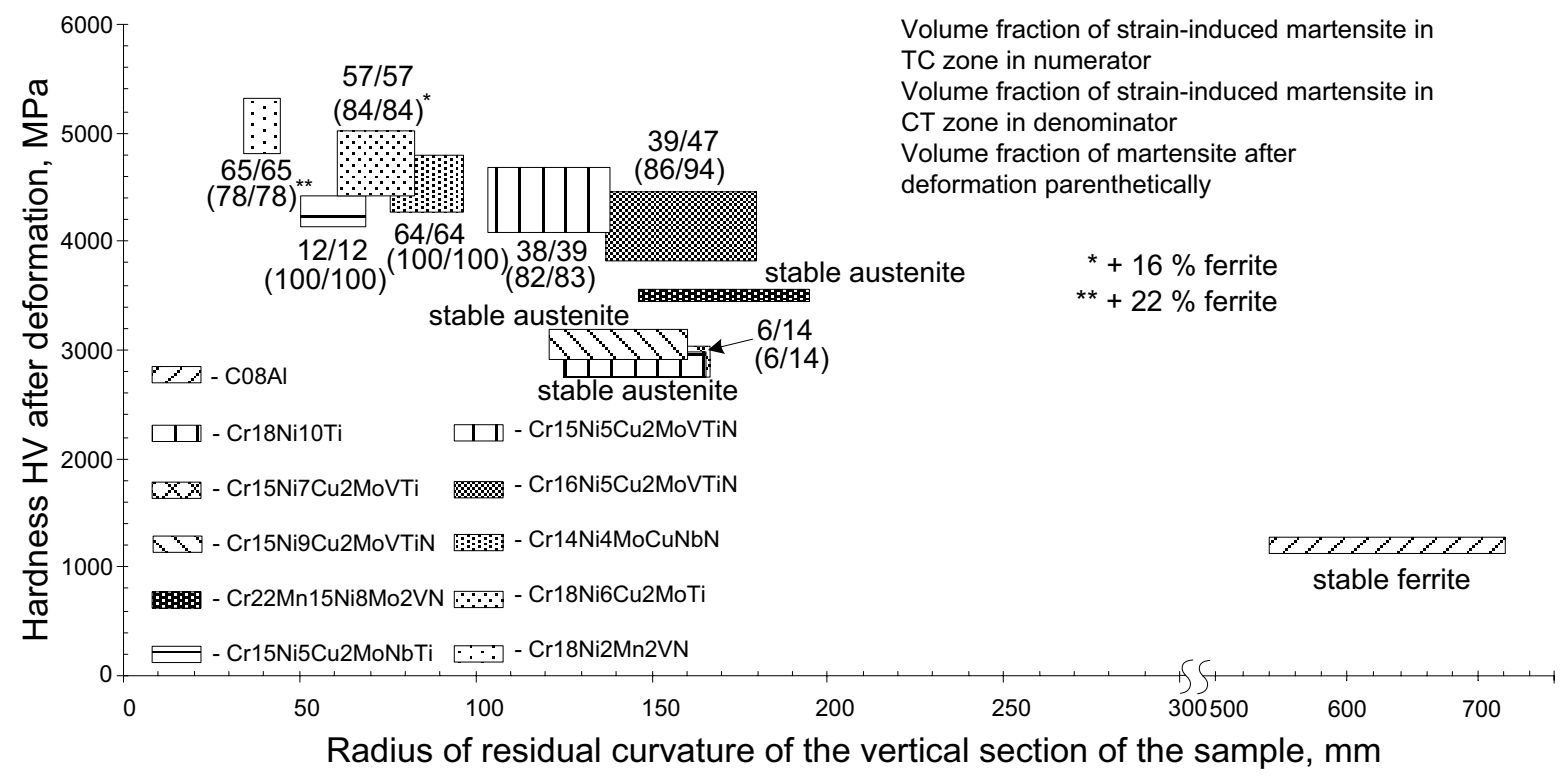

Fig 3. Dependence of elastic aftereffect on hardness and martensitic transformation under loading in steels.

Measurements of the residual stresses in the internal and external surfaces of vertical parts of samples (Table 2) have showed that if transformation has been completed in martensitic state $(\mathrm{Cr} 15 \mathrm{Ni} 5 \mathrm{Cu} 2 \mathrm{MoNbTi}$, Cr18Ni6Cu2MoTi and Cr18Ni2Mn2VN steels) tensile residual stress act in internal surface of the sample (TC zone) while the compressive residual stress in external surface. In the case of the martensitic transformation was incomplete and deformation finished in martensitic-austenitic state (Cr15Ni5Cu2MoVTiN and Cr16Ni5Cu2MoVTiN steels) an opposite effect was observed, compressive residual stress in internal surface, 
while tensile in external surface. Residual stress was close to zero in internal surface for deformed stable austenitic steel while in external surface, a low tensile stress acted for deformed stable austenitic steels.

Table 2. Residual stresses in initial samples and after deformation

\begin{tabular}{|c|c|c|c|c|}
\hline \multirow[b]{2}{*}{ Steel grade } & \multirow{2}{*}{$\begin{array}{c}\text { For } \\
\text { crystal } \\
\text { plane }\end{array}$} & \multicolumn{3}{|c|}{ Average volume of residual stresses ${ }^{*}, \mathrm{MPa}$} \\
\hline & & Initial state & $\begin{array}{c}\text { After tension } \\
\text { and compression }\end{array}$ & $\begin{array}{c}\text { After compression and } \\
\text { tension }\end{array}$ \\
\hline C08Al & $211 \alpha$ & -42 & $\mathrm{n} / \mathrm{a}$ & +93 \\
\hline Cr18Ni10Ti & $220 \gamma$ & $\approx+100$ & low tension & low tension \\
\hline Cr15Ni7Cu2MoVTiN & $220 \gamma$ & +133 & +39 & +178 \\
\hline Cr14Ni9Cu2MoVTiN & $220 \gamma$ & -117 & -16 & $\mathrm{n} / \mathrm{a}$ \\
\hline $\mathrm{Cr} 15 \mathrm{Ni} 5 \mathrm{Cu} 2 \mathrm{MoNbTi}$ & $211 \alpha$ & -306 & +254 & -514 \\
\hline Cr15Ni5Cu2MoVTiN & $211 \alpha$ & $\mathrm{n} / \mathrm{a}$ & -551 & +276 \\
\hline Cr16Ni5Cu2MoVTiN & $211 \alpha$ & $\mathrm{n} / \mathrm{a}$ & -508 & +347 \\
\hline $\mathrm{Cr} 14 \mathrm{~N} 4 \mathrm{MoCuNbN}$ & $211 \alpha$ & -392 & -510 & +179 \\
\hline Cr18Ni6Cu2MoTi & $211 \alpha$ & -537 & +237 & -361 \\
\hline Cr18Ni2Mn2VN & $211 \alpha$ & -141 & +115 & -352 \\
\hline
\end{tabular}

${ }^{*}$ evaluation precision is no more than $\pm 20 \mathrm{MPa}$

The stress relaxation curves of the studied steels during exposure under load (State standard GOST 2700783) are shown in Fig. 4. The stress relaxation is most intensive during $5-10$ second. For Cr15Ni5Cu2MoVTiN and $\mathrm{Cr} 16 \mathrm{Ni} 5 \mathrm{Cu} 2 \mathrm{MoVTiN}$ steels, the main stress relaxation occurs during 2 minutes while for other steels almost completes in 1 minute after the loading stop. That may be the result of the martensitic transformation under loading in the two-phase austenitic-martensitic metastable steels. The Cr18Ni10Ti, Cr18Ni6Cu2MoTi and $\mathrm{Cr} 18 \mathrm{Ni} 2 \mathrm{Mn} 2 \mathrm{VN}$ steels have the lowest stress relaxation rate. The stress relaxation for $\mathrm{Cr} 18 \mathrm{Ni} 6 \mathrm{Cu} 2 \mathrm{MoTi}$ and $\mathrm{Cr} 18 \mathrm{Ni} 2 \mathrm{Mn} 2 \mathrm{VN}$ steels is less pronounced due to higher stress under loading.

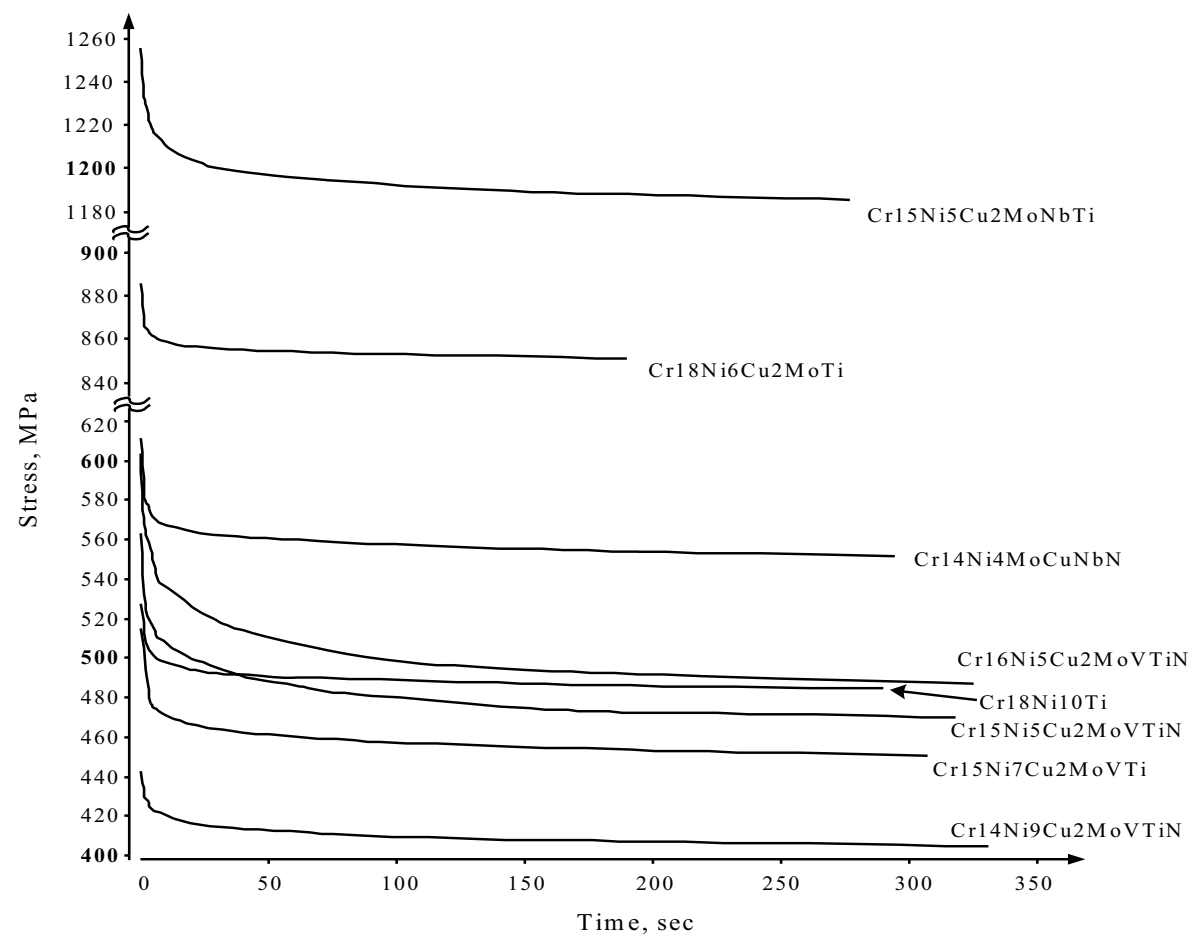

Fig. 4. Stress relaxation curves. 
The U-test analytical model which considers phase transformations and stress relaxation in test has been developed taking into account the experimental data.

The stress relaxation was taken into account by means of calculated active stress in material and approximate parameters of stress relaxation curves. It has been assumed that the strain state of material after exposure under load is practically constant. The stress distribution across thickness during post-deformation exposure is given by:

$$
\sigma(z)_{\text {relax. }}=\frac{\sigma(z) \cdot \mathrm{A}}{\sigma_{0}} \cdot \tau^{\mathrm{b}}
$$

where $\sigma(z)$ - stress distribution across thickness immediately after deformation;

$\sigma_{0}, \mathrm{~A}, \mathrm{~b}-$ stress relaxation curve parameters, the stress relaxation curve is approximated by $\sigma=\sigma_{0}-A \cdot \tau^{b}$

$$
\tau \text { - stress relaxation time. }
$$

Comparison of the calculated elastic aftereffect parameters with the experimental ones shows a good correlation of the results (Fig. 5).

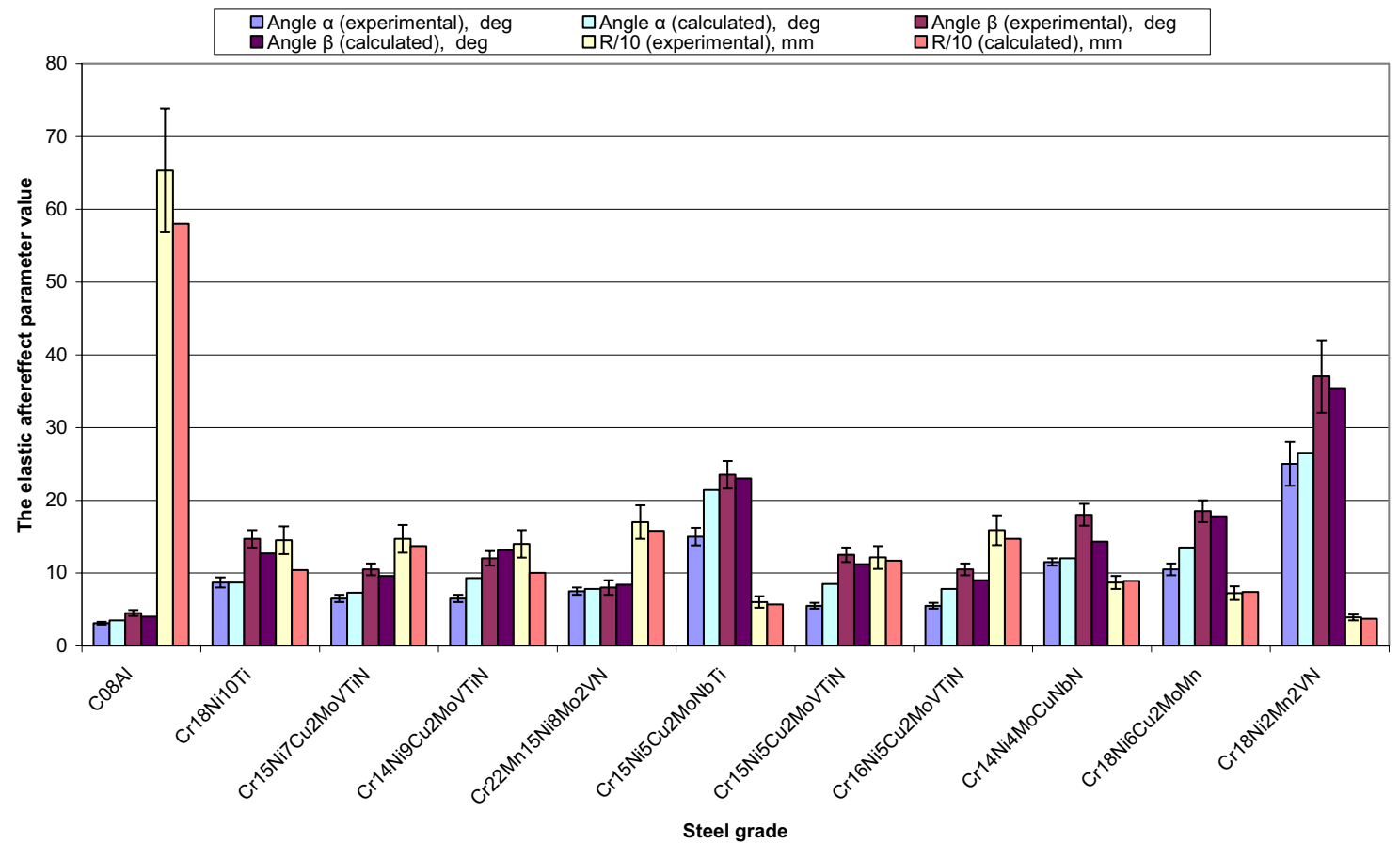

Fig. 5. Comparison of calculated and experimental elastic aftereffect parameters.

The authors are grateful to D.Sc. V. Blinov and Ph.D. I. Afanasiev (Baikov Institute of Metallurgy and Materials Science, Moscow, Russia) for steel samples supply and Prof. V. Kanev, Ph.D. A. Lutsau, Ph.D. A. Kotelkin, Ph.D. D. Matveev and Ph.D. A.D. Zvonkov (Moscow Institute of Steel and Alloys) for their help in experimental work.

\section{Conclusions}

1. Different nature of mechanical behavior for steels of different structural classes, deformation hardening dependence on martensitic transformation under loading and sequence of alternating loading have been experimentally demonstrated. 
2. The elastic aftereffect in sheet steels depends on initial structure and increases in following sequence: ferrite, austenite, martensite. The elastic aftereffect increases as the martensite structure volume fraction increases. It is the highest in completely martensite steels.

3. The elastic aftereffect in metastable steels depends on martensite fraction in initial state and martensite transformation kinetics under loading. Transformation under loading is in complete and presence of retained austenite in deformed structure decrease the elastic aftereffect due to strain-induced martensite formation as well as to higher stress relaxation rate in material.

4. An adequate mathematical model for stamping test of sheet steels taking into account phase transformations and stress relaxation has been developed.

\section{References}

[1] T. Hildich, J. Speer, D. Matlock, Steel GRIPS, No. 3, 209-211 (2004).

[2] I. Inkin, Study and modeling for deformation cold rolled sheet stable and metastable steels. Ph.D. thesis, Moscow, 2004, p. 83-84.

[3] L. Kaputkina, I. Inkin, A. Skugorev, T. Afanasieva, V. Blinov, I. Afanasiev, Metally, No. 2, 63-68 (2007).

[4] A. Lutsau, A. Kotelkin, D. Matveev, A. Zvonkov, "Stress analysis of various material by PRD portable diffractometer", Conference, Colorado, USA, 4-8 August 2003, D038. 